\title{
CRISPR/Cas9 ADCY7 Knockout Stimulates the Insulin Secretion Pathway Leading to Excessive Insulin Secretion
}

\author{
Yazeid Alhaidan 1,2,3,4*, Henrik Thybo Christesen ${ }^{2,5,6}$, Elena Lundberg ${ }^{7}$, \\ Mohammed A. Al Balwi ${ }^{3,4,8}$ and Klaus Brusgaard ${ }^{1,2,9}$ \\ ${ }^{1}$ Department of Clinical Genetics, Odense University Hospital, Odense, Denmark, ${ }^{2}$ Department of Clinical Research, Faculty \\ of Health Sciences, University of Southern Denmark, Odense, Denmark, ${ }^{3}$ Department of Medical Genomics Research, King \\ Abdullah International Medical Research Center, Riyadh, Saudi Arabia, ${ }^{4}$ King Saud Bin Abdulaziz University for Health \\ Sciences, Riyadh, Saudi Arabia, ${ }^{5}$ Hans Christian Andersen Children's Hospital, Odense University Hospital, Odense, \\ Denmark, ${ }^{6}$ Odense Pancreas Center, Odense, Denmark, ${ }^{7}$ Institute of Clinical Science, Pediatrics, Umea University, Umeå, \\ Sweden, ${ }^{8}$ Department of Pathology and Laboratory Medicine, King Abdulaziz Medical City, NGHA, Riyadh, Saudi Arabia, \\ ${ }^{9}$ Near East University, Nicosia, Cyprus
}

OPEN ACCESS

Edited by:

Åke Sjöholm,

Gävle Hospital, Sweden

Reviewed by:

Amanda Ackermann, Children's Hospital of Philadelphia,

United States

Diana Stanescu,

Children's Hospital of Philadelphia,

United States

*Correspondence:

Yazeid Alhaidan

yazeid@mail.net.sa

Specialty section:

This article was submitted to Diabetes: Molecular Mechanisms,

a section of the journal

Frontiers in Endocrinology

Received: 26 January 2021 Accepted: 18 May 2021

Published: 11 June 2021

Citation:

Alhaidan Y, Christesen HT,

Lundberg E, Balwi MAA and Brusgaard K (2021) CRISPR/Cas9

ADCY7 Knockout Stimulates the Insulin Secretion Pathway Leading to

Excessive Insulin Secretion.

Front. Endocrinol. 12:657873. doi: 10.3389/fendo.2021.657873
Aim: Despite the enormous efforts to understand Congenital hyperinsulinism (CHI), up to $50 \%$ of the patients are genetically unexplained. We aimed to functionally characterize a novel candidate gene in $\mathrm{CHI}$.

Patient: A 4-month-old boy presented severe hyperinsulinemic hypoglycemia. A routine $\mathrm{CH}$ genetic panel was negative.

Methods: A trio-based whole-exome sequencing (WES) was performed. Gene knockout in the RIN-m cell line was established by CRISPR/Cas9. Gene expression was performed using real-time PCR.

Results: Hyperinsulinemic hypoglycemia with diffuse beta-cell involvement was demonstrated in the patient, who was diazoxide-responsive. By WES, compound heterozygous variants were identified in the adenylyl cyclase 7, ADCY7 gene p.(Asp439Glu) and p.(Gly1045Arg). ADCY7 is calcium-sensitive, expressed in beta-cells and converts ATP to CAMP. The variants located in the cytoplasmic domains $\mathrm{C} 1$ and $\mathrm{C} 2 \mathrm{in}$ a highly conserved and functional amino acid region. $\mathrm{RIN}-\mathrm{m}^{(-/- \text {Adcy })}$ cells showed a significant increase in insulin secretion reaching 54\% at low, and $49 \%$ at high glucose concentrations, compared to wild-type. In genetic expression analysis Adcy7 loss of function led to a 34.1-fold to 362.8-fold increase in mRNA levels of the insulin regulator genes Ins1 and Ins2 ( $p \leq 0.0002)$, as well as increased glucose uptake and sensing indicated by higher mRNA levels of Scl2a2 and Gck via upregulation of $P d x 1$, and Foxa2 leading to the activation of the glucose stimulated-insulin secretion (GSIS) pathway.

Conclusion: This study identified a novel candidate gene, $A D C Y 7$, to cause $\mathrm{CHI}$ via activation of the GSIS pathway.

Keywords: genetics, metabolomics, congenital hyperinsulinism, hyperinsulinemic hypoglycemia, pediatrics, adenylyl cyclase 


\section{INTRODUCTION}

Congenital hyperinsulinism (CHI) is a rare disease characterized with dysregulated insulin secretion from the pancreatic $\beta$-cells pancreatic leads to hyperinsulinemic hypoglycemia $(1,2)$. CHI is a heterogeneous disorder in terms of both phenotype and genotype. The rareness, severity, and complexity of $\mathrm{CHI}$ often lead to delayed and insufficient management with a high risk of subsequent brain damage mental retardation (3).

The estimated incidence of $\mathrm{CHI}$ is $1: 40,000$ in 50,000 newborns, but considerably higher in certain populations, e.g., 1:2,500 newborns in Saudi Arabia (4). The management of CHI is highly dependent on the major histological forms: focal or diffuse. ${ }^{18} \mathrm{~F}$-fluoro-L-dihydroxyphenylalanine (18F-DOPA) PET/CT scan shows excellent performance in the identification of focal $\mathrm{CHI}$, which is curable by limited pancreatic resections (5, 6). Milder forms of CHI response to medical treatment with diazoxide or somatostatin analogues, and an appropriate diet. Severe diffuse CHI with poor medical response, may require subtotal pancreatectomy, however imposing a high risk of subsequent diabetes (7). A medical approach is therefore encouraged, e.g. with long-acting octreotide (8).

Genetically, variants in at least nine genes have been identified as causes of CHI; ATP-Binding Cassette, subfamily $\mathrm{C}$, member 8 (ABCC8) and Potassium Channel, Inwardly rectifying, subfamily J, member 11 (KCNJ11), which constitute the $\mathrm{K}^{+}$ATP channel of the beta cell, accounts for most cases (9, 10). Less frequently, activating variants in the glucokinase gene $(G C K)(11)$, or variants in the glutamate dehydrogenase gene (GLUD1) (12), or inhibitory variants in $H A D H$ (shortchain L-3hydroxyacyl-coenzymeA dehydrogenase) (13), the monocarboxylase transporter (SLC16A1) (14), the uncoupling protein (UCP2) (15), HNF4A (hepatocyte nuclear factor 4 alpha) (16), and HNF1 homeobox alpha (HNF1A) (17). Recently, abnormalities in three new genes have been linked to $\mathrm{CHI}$ hexokinase 1 (HK1), phosphoglucomutase 1 (PGM1), and phosphomannomutase 2 (PMM2) genes (18-20). In addition, several syndromes are associated with $\mathrm{CHI}$ such as BeckwithWiedemann, Sotos, Kabuki, Usher, Timothy, Costello, Trisomy 13, and Mosaic Turner syndrome (21).

Despite the enormous efforts to understand this condition, up to $50 \%$ of patients still have negative investigations in the known pathogenic genes. This poses a challenge for both the geneticist and physician, as genotype-phenotype correlations provide a basis for targeted treatment. Here, we report a patient with $\mathrm{CHI}$ of unknown genetic cause by routine investigations. Functional studies carried out by generating a knockout cell line identified a novel candidate gene involved in hypersecretion of insulin.

\section{MATERIALS AND METHODS}

\section{Trio-Based Whole-Exome Sequencing}

DNA was extracted from whole blood using The Maxwell ${ }^{\circledR}$ RSC Blood DNA Kit from Promega. The proband was forwarded for a clinical CHI gene panel and subsequent a trio-based whole- exome sequencing (WES) approach. DNA samples obtained from our patient and his parents were subjected to exome capture using Roche NimbleGen SeqCap EZ Exome 3.5v Enrichment Kits (Roche, Hvidovre, Denmark) and sequencing was performed on the Illumina HiSeq 1500 platform. Raw reads were processed using the Burrows-Wheeler Alignment tool (BWA-MEM) v. 0.7.12, and the GATK Best Practice pipeline v. 3.3-0 was used for variant calling. A mean read depth of $63.6 \mathrm{x}$ was obtained.

\section{Data Analysis}

VarSeqTM (Golden Helix, Inc., Bozeman, MT) was used for downstream filtering. All variants were first filtered with a minimum of $10 \times$ coverage, non-synonymous, and presented in the exome region or splice sites, which represented $94.4 \%$ of the targeted bases. Filtered variants were then processed twice, one for each parameter as previously described (22) The first parameter, which covers the possibility of a compound heterozygous, an autosomal recessive, a multifactorial, or de novo, was set to a population frequency of $\leq 0.01$ (GenomAD and $\mathrm{ExAC}$ ). The second parameter, which covers the dominant inheritance of single nucleotide polymorphisms (SNPs) and small insertions and deletions (INDELs), was set to a frequency of $\leq 0.000025$ for $\mathrm{CHI}$.

To examine known causal genes that have been reported in the literature including related genes and pathways, a gene list was generated consisting of 6,264 genes categorized by disorders, pathways, expression, AmiGO terms, and other into 26 sublists (23). This was performed through an extensive literature review using PubMed, Ovid ${ }^{\circledR}$, GeneCards ${ }^{\circledR}$, and the National Center for Biotechnology Information (NCBI).Furthermore, we used gene and protein expression databases such as BioGPS and The Human Protein Atlas, protein interactions and gene network databases such as AmiGO, BioGRID, GIANT, KEGG, and Reactome, knockout mouse databases such as MGI and IMPC. However, filtering against the gene list will not replace the manual screening for all variants called; therefore, we did not consider the results of our gene list alone. Once the raw data were obtained, they were filtered and investigated individually. Variants went through serial steps ending up with a single nucleotide polymorphism variant as a potential explanation. Pathogenicity scores were determined by SIFT, PolyPhen-2, PANTHER, SNPs\&GO, and nsSNPAnalyzer.

\section{Cell Culture}

RIN-m cell line was purchased from American Type Culture Collection (LGC Standards GmbH, Wesel, Germany) and maintained in RPMI-1640 medium (ATCC) supplemented with $10 \%$ fetal bovine serum (FBS: Biological Industries) and $100 \mathrm{U}$ penicillin and $100 \mu \mathrm{g} / \mathrm{ml}$ streptomycin (P4333:SIGMA) in a humidified incubator at $5 \% \mathrm{CO}_{2}$ and $37^{\circ} \mathrm{C}$.

\section{Knockout of Adcy 7 by CRISPR/Cas 9}

CRISPR/Cas9 guide-RNA targeting exon 5 in rat Adcy7 (5'TACCCATGGAGATGTGAGCT $-3^{\prime}$ ) was manually designed using https://benchling.com and Alt- $\mathrm{R}^{\circledR}$ S.p. Cas9 Nuclease 
3NLS were ordered from (Integrated DNA Technologies, BVBA, Belgium). Lipofectamine ${ }^{\circledR}$ RNAiMAX (Thermo Fischer, Naerum, Denmark) was used for transfection in Opti-MEM ${ }^{\mathrm{TM}}$ medium according to the manufacturer's instructions. In short, knockout was performed by mixing $24 \mu \mathrm{l}$ of $1 \mu \mathrm{M}$ gRNA with $24 \mu \mathrm{l}$ of $1 \mu \mathrm{M}$ Cas9 Nuclease in $352 \mu$ l Opti-MEM ${ }^{\circledR}$ Medium for 5 minutes to assemble the RNP complex. RNP complexes were mixed with $19.2 \mu \mathrm{l}$ Lipofectamine ${ }^{\circledR}$ RNAiMAX in $380 \mu \mathrm{l}$ OptiMEM $^{\circledR}$ Medium for 20 minutes to form transfection complexes. This was subsequently transferred to $1.6 \mathrm{ml}$ of the complete medium without an antibiotic-antimycotic solution containing $6.4 \times 10^{5}$ cells in 6 well plate. Cells were then incubated in a humidified incubator at $5 \% \mathrm{CO} 2$ and $37^{\circ} \mathrm{C}$ for 72 hours prior to sequencing. Validated edited cells were then diluted and cultured at low cell concentration to isolate single cell colonies and establish a knockout $A d c y 7$ cell line, RIN-m ${ }^{(-/-A d c y 7)}$.

\section{Sanger Sequencing}

Gene editing was validated using BigDye Terminator v. 3.1 cycle sequencing kit and an ABI 3730xl capillary sequencer (Thermo Fischer, Naerum, Denmark). Adcy7 primers targeting exon 5 in RIN-m cell line were ordered from Integrated DNA Technologies, BVBA, Belgium (forward 5' - ACAGGGAGGGCACATACTCT -3', reverse 5' - AAATCCCCAGAGACACGCTC -3').

\section{Stimulus Insulin Secretion of $\beta$-Cells}

Both RIN-m ${ }^{(-/-A d c y 7)}$ and RIN-m ${ }^{\text {WT }}$ were cultured for 24 hours prior to stimulation. This was performed by culturing $5 \times 10^{5}$ cells in $2 \mathrm{ml}$ of complete medium in 6 well plate. Krebs-RingerHEPES buffer (KRHB) was prepared $(118 \mathrm{mM} \mathrm{NaCl}, 5.4 \mathrm{mM}$ $\mathrm{KCl}, 2.4 \mathrm{mM} \mathrm{CaCl}_{2}-2 \mathrm{H}_{2} \mathrm{O}, 1.2 \mathrm{mM} \mathrm{MgSo}_{4}, 1.2 \mathrm{mM} \mathrm{KH}_{2} \mathrm{Po}_{4}, 20$ $\mathrm{mM}$ HEPES and $0.2 \% \mathrm{BSA}$ ) to be used for washing and stimulation experiments. Cells were washed twice with KRHB containing $1.1 \mathrm{mM}$ glucose before starving for one hour in $1 \mathrm{ml}$ KRHB containing $1.1 \mathrm{mM}$ glucose. After starvation, cells were washed twice with $\mathrm{KRHB}$ containing $1.1 \mathrm{mM}$ glucose and incubated in $2 \mathrm{ml} \mathrm{KRHB}$ containing $2 \mathrm{mM}$ or $10 \mathrm{mM}$ glucose to measure insulin secretion at low and high concentrations. Both cells and media were then collected to perform mRNA and insulin measurements. Each experiment was performed in triplicate.

\section{Real-Time PCR}

Total RNA was extracted using an RNeasy Mini Kit (Qiagen, Copenhagen). The SuperScript ${ }^{\circledR}$ III first-strand synthesis system (Thermo Fischer, Naerum, Denmark) was used for cDNA synthesis. The StepOne ${ }^{\mathrm{TM}}$ system (Thermo Fischer, Naerum, Denmark) was used for real-time PCR using the TaqMan ${ }^{\circledR}$ PreAmp Master Mix Kit and Expression Assay ID (Adcy7; Rn01538046_m1, Actb; Rn00667869_m1, Ins1; Rn02121433_g1, Ins2; Rn01774648_g1, Prkaca; Rn01432300_g1, Prkacb; Rn01748540_g1, Rapgef4; Rn01514839_m1, Slc2a2; Rn00563565_m1, Pdx1; Rn00755591_m1, Gck; Rn00561265_m1, and Foxa2; Rn01415600_m1) (Thermo Fischer, Naerum, Denmark). All data were analyzed using $\beta$-actin (Actb) expression as an endogenous control (Supplemental Data).

\section{Insulin Measurement by ELISA}

A rat Insulin ELISA kit (cat n. ERINS) (Thermo Scientific, Naerum, Denmark) was used according to the manufacturer's instructions. The Victor ${ }^{\mathrm{TM}}$ X5 Multilabel Plate Reader was used to measure the absorbance (PerkinElmer, Skovlunde, Denmark).

\section{Data Analysis}

All experiments were performed in triplicate. Changes in cycle threshold (CT) and total insulin concentrations between knockout and wild-type were calculated with an unpaired ttest. Data were presented as the mean and standard error of the means (mean \pm SEM).

\section{Ethics}

Oral and written consent was obtained from all participants. The study was approved by The Regional Ethical Committee of Southern Denmark (number. S-VF-20040235)

\section{RESULTS}

\section{Patient}

A non-syndromic, Swedish Caucasian boy without Finnish inheritance was born at term, birth weight $3670 \mathrm{~g}$, birth length $52 \mathrm{~cm}$, with an uneventful neonatal period. He presented at age of 4 months weight $7460 \mathrm{~g}$ (+1SDS), length $68 \mathrm{~cm}$ (0 SDS) with hypoglycemic convulsions and loss of consciousness. At blood glucose $1.6 \mathrm{mM}$, p-insulin was $19 \mathrm{mU} / \mathrm{L}$ with no ketone body detected, confirming a diagnosis of CHI. An 18F-DOPA PET/ CT scan showed diffuse pancreatic involvement.

Initially, he responded to treatment with diazoxide $10 \mathrm{mg} / \mathrm{kg} /$ day, divided into 3 doses. His growth followed +1 SDS in weight and 0 SDS in height according to the Swedish growth reference. His psychomotor development was normal. Diazoxide dose was reduced to $2 \mathrm{mg} / \mathrm{kg} /$ day from 4 to 7 years of age, but increased to $4 \mathrm{mg} / \mathrm{kg} /$ day at the latest follow-up age 9 years.

No variants were found by a clinical next-generation sequencing panel of nine genes related to $\mathrm{CHI}$ as previously described (5).

\section{Sequencing Analysis}

Trio WES analysis revealed compound heterozygous variants in the Adenylyl Cyclase 7 ( $A D C Y 7)$ gene. A paternal variant, NM_001114.4: c.1317C>A, p.(Asp439Glu) and a maternal variant, c.3133G $>$ A, p.(Gly1045Arg), were found. These variants are located in the cytoplasmic domains $\mathrm{C}_{1}$ and $\mathrm{C}_{2}$, respectively, (Figure 1) in a highly conserved amino acid region $(24,25)$. The ConSurf server for the identification of functional regions in proteins predicted both amino acids to play a functional role and being exposed to an interaction site. The prediction software SIFT, PolyPhen-2, PANTHER, SNPs\&GO, and nsSNPAnalyzer predicted both variants to be deleterious. $A D C Y 7$ is reported to be expressed in pancreatic tissue with other isoforms $A D C Y 1, A D C Y 3, A D C Y 5$, and ADCY9 (26). Adenylyl cyclases (ACs) are a family of ten different mammalian isoforms that converts ATP to cyclic AMP. $A D C Y 7$ is a membrane-bound member of this family, reported to be inhibitable by calcium. 

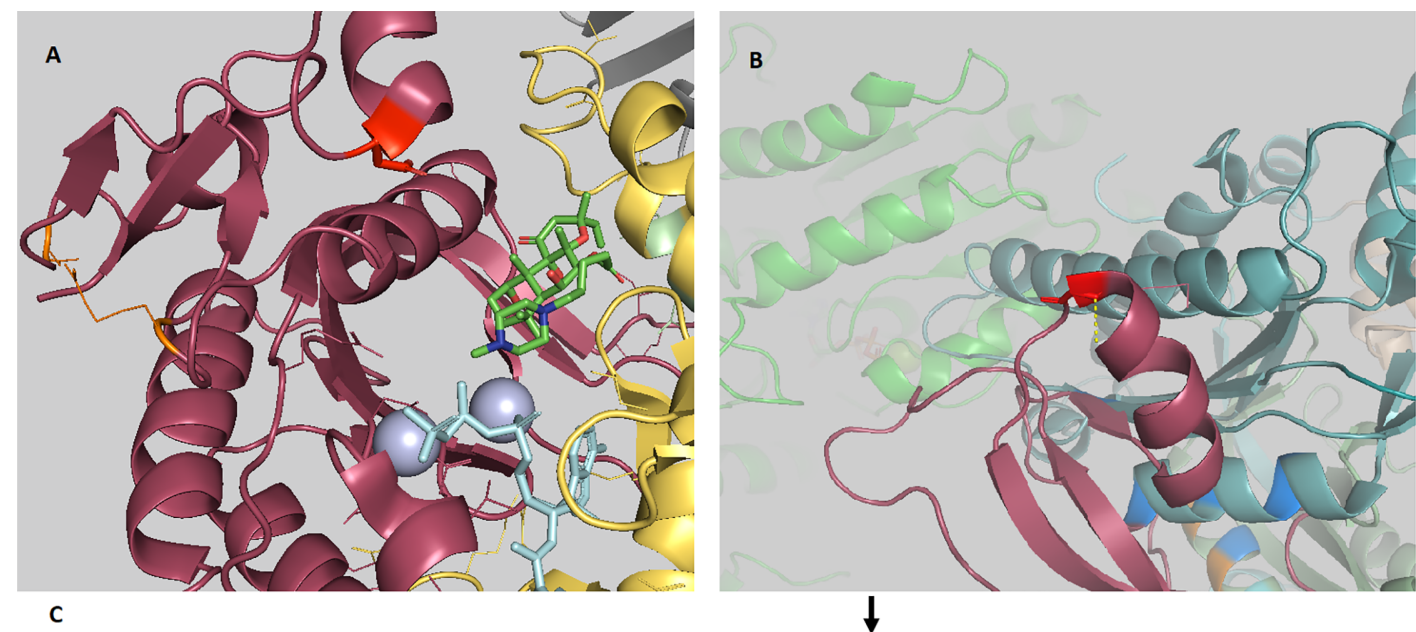

C

ANRMESAGVPGRVHI TEATLNHL dKA-YEVExGHGh-QRDPYLKEMNIKTYLVIDPRS Q QPPPPS $n$ HLPKP $x$ dd $g$ LKMRASVRMTRYLESWGAAR

Consensus

NP_001105.1

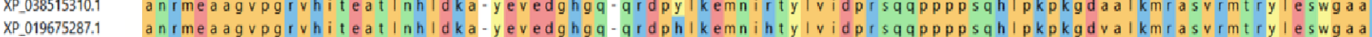
NP_45848.1 anrmeagavpgrvhiteat Inh I dka-yevedghge-grdpy|kemnirty|vidprsqqpp|pshh|skpkgdat |kmrasvivtry|eswgaa anrme a grporvhiteat l nhldka-yevedghoe-

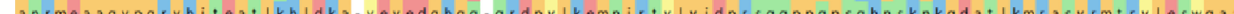
anrmessgipgrvhiteat inhigka-yeveegngh- Irdpyleamniktylvidprskqrtionnhipktrunglkmrasvimt ryleswgaa

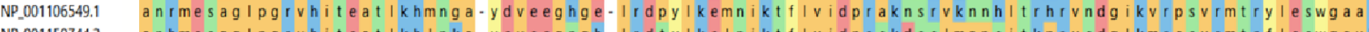
NP_001159744.2 anhmesgglpgrvhiteat I kh I nka-yeveegngh- Irdtylkelnikt f Ividprskdss Imapsitkprvsdg|kmrasvrmtrf leswgav XP_037264645.1 anrmesagvpgrvhiteat Inhlgka-yeveegngh-1 rdpylesmniktylvvdprskqcis-nnh|pkt r vadg|kmrasvimtry|eswgaa XP_015147888.1 anrmesagvpgrvhiteat Inhlgka-yeveegngh-Irdpylesmnikty|vvdprskqcks-nnh|pktrvndg|kmrasvimtry|eswgaa

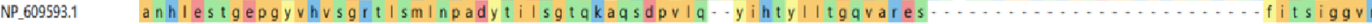

Sequence Logo

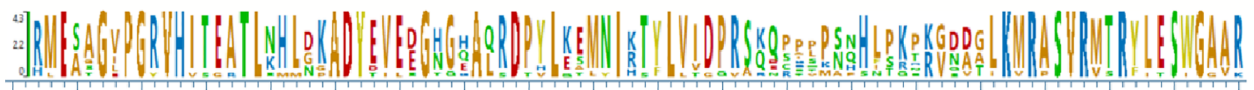

D

Consensus

NP_001105.1

XP_038515310.1 XP_019675287.1 NP_445848.1

NP 031432.2

NP 776655.1

XP_039208357.1

XP 034644771.1

NP_001106549.1

NP_001159744.2

XP_037264645.1

XP_015147888.1

NP_609593.1

agvigarkpqydiwgntvnvas rmestgelgkiqvteetctilqglgyscecrglinvkgkgelrtyfvctd agvigarkpqydiwgntvnvasrmestgelgkiqvteetctilqglgyscecrglinvkgkgelrtyfvctd agvigarkpqydiwgntvnvas rmestgelgkiqvteetctilqglgyscecrglinvkgkgelrtyfvcto agvigarkpqydiwgnt vnvas rmestgelgkiqvteetctilqglgyscecrglinvkgkgelrtyfvctd agvigarkpqydiwgntvnvas rmestgelgkiqvteetctilqglgyscecrglinvkgkgelrtyfvctd agvigarkpqydiwgnt vnvasrmestgelgkiqvteetctilqglgyscecrglidvkgkgelrtyfuctd agvigarkpqydiwgnt vnvas rmettgelgkiqvteetckilks Igyacecrglinvkgkgelityfvctd agvigarkpqydiwgntvnvas rmestgelgkiqvteetskilqelgyscecrglinvkgkgelrtyfvcto agvigakkpqydiwgntvnvas rmestgelgkiqvteetcqi leglgyscecrgfinvkgkgelrtyfvctd agvigarkpqydiwgntvnvas rmestgelgkiqvteetsiviqn Igyscecrglinvkgkgelktffvctd agvigarkpqydiwgnt vnvasrmestgelgkiqvteetskilqelgyscecrglinvkgkgelrtyfvcte agvigarkpqydiwgntvnvasrmestgelgkiqvteetsrilqdlgyscecrglinvkgkgelrtyfvcte agvvgasqphydiwgnpvnmas rmestglpghiqvteesaki Iqefdikciyrgmtfvkgrgdiptyfvgid

Sequence Logo

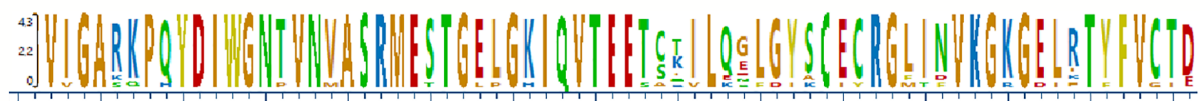

FIGURE 1 | ADCY7 variants crystal structure. (A) The crystal structure of Gos.VC1.IIC2 domain in complex with the substrate analog TNP-ATP based on pdb 2GVZ; ADCY5. The Asp439 residue is depicted as a red tooth stick. The adenylate cyclase inhibitor foskolin shown as green tooth sticks and the TNP-ATP substrate analog as aquamarine tooth sticks. The two manganese ions in grey. Two residues are depicted in orange are mutated in GUCY2D causing Leber congenital amaurosis 1. VC1 in salmon, IIC2 in yellow, Gas in grey. Residues involved in VC1.IIC2 interaction shown as tooth sticks. (B) The crystal structure of the IIC2 domain based on pdb 6R4P; ADCY9. Gly1045 shown in red with a polar interaction indicated by a yellow dashed line to the backbone of residue Gly1043. Gly1043 allow a sharp turn to the loop connecting $\alpha$-helix 15 and $\beta$-strand 19. Replacing Gly1045 with arginine can be predicted to prevent this turn. Residues depicted in blue are mutated in GUCY2D causing Leber congenital amaurosis 1. In the background the VC1 domain (green) can be seen. (C) Alignment of $A D C Y 7$ sequences displaying conservation from homo sapiens at the top to Drosophila melanogaster at the bottom. Asp439 indicated by an arrow. (D) Alignment of $A D C Y 7$ sequences displaying conservation from homo sapiens at the top to Drosophila melanogaster at the bottom displaying conservation of Gly1045 indicated by an arrow.

\section{Protein Sequence Analysis}

The three-dimensional protein structure of candidate genes was analyzed using PyMOL v.1.7.4 (Schrödinger, New York, USA). (PDB-ID: 2GVZ).

\section{Cell Line Establishment}

An $A d c y 7$ knockout cell line, RIN-m ${ }^{(--A d c y 7)}$, was established and validated, (Figure 2A). A one base insertion located in exon 5 created a frameshift leading to generation of a premature 
termination codon located 11 codons downstream (Figure 2B). In addition, the $A d c y 7$ mRNA level determined by real-time PCR confirmed the loss of the expression as a result of degradation via nonsense-mediated mRNA decay (Figure 2C).

\section{Adcy7 Knockout Shows an Excessive Insulin Expression and Secretion}

To investigate whether $A d c y 7$ influences the insulin secretion genes Ins 1 and Ins2, cells were incubated in low $2 \mathrm{mM}$ and high $10 \mathrm{mM}$ glucose concentration and mRNA was measured. The levels of both Ins1 and Ins2 mRNA displayed a statistically significant increase in absence of Adcy7 gene expression. The regulator of insulin gene expression, Ins1 was significantly increased by 362.8 fold $(p<0.00001)$ at low glucose media $2 \mathrm{mM}$, and by 320.9 fold $(p<0.00001)$ at high glucose media $10 \mathrm{mM}$ (Figure 3A). The secretion regulator Ins2 was also dramatically increased by 43.6 fold $(p=0.00001)$ at low glucose concentration and by 34.1 fold $(p=0.00002)$ at high glucose concentration for RIN-m $\mathrm{m}^{(-/-A d c y 7)}$ cells compared to the wildtype (Figure 3B).

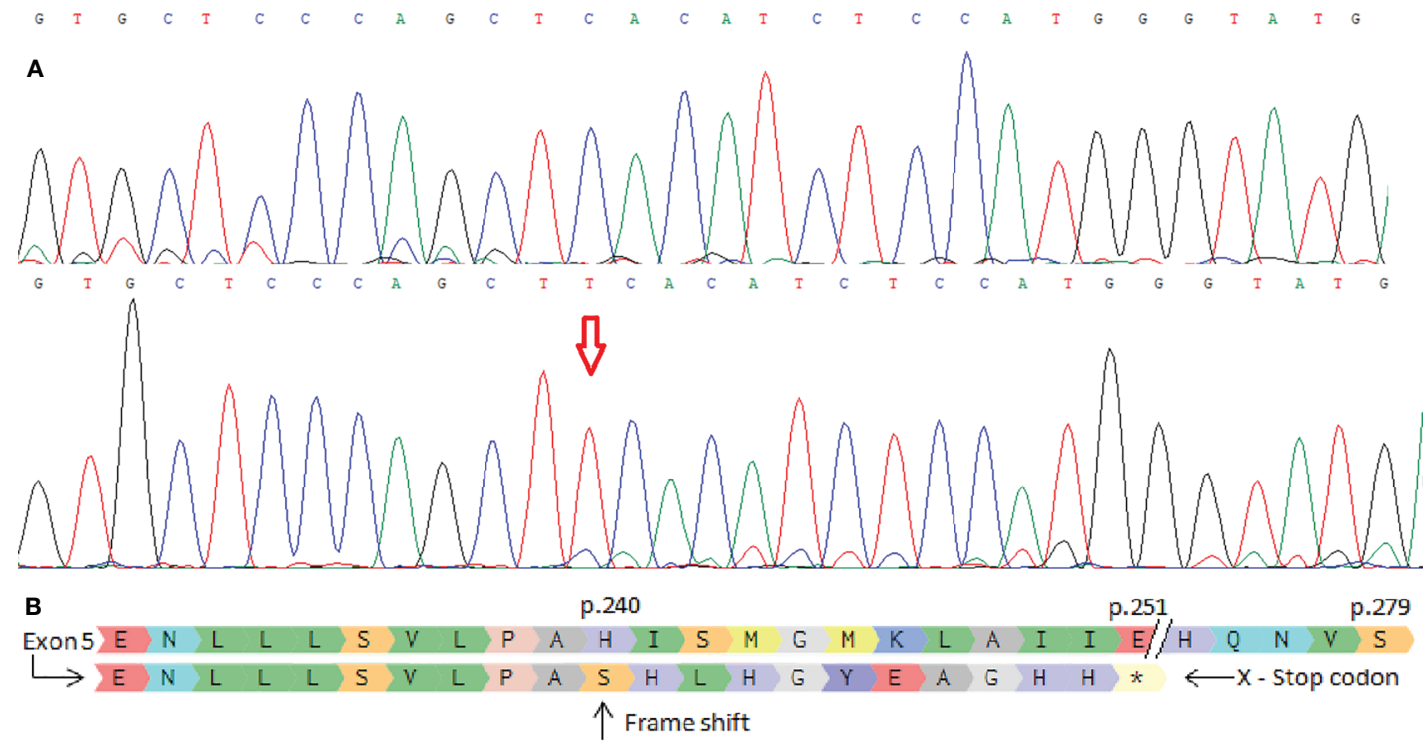

C

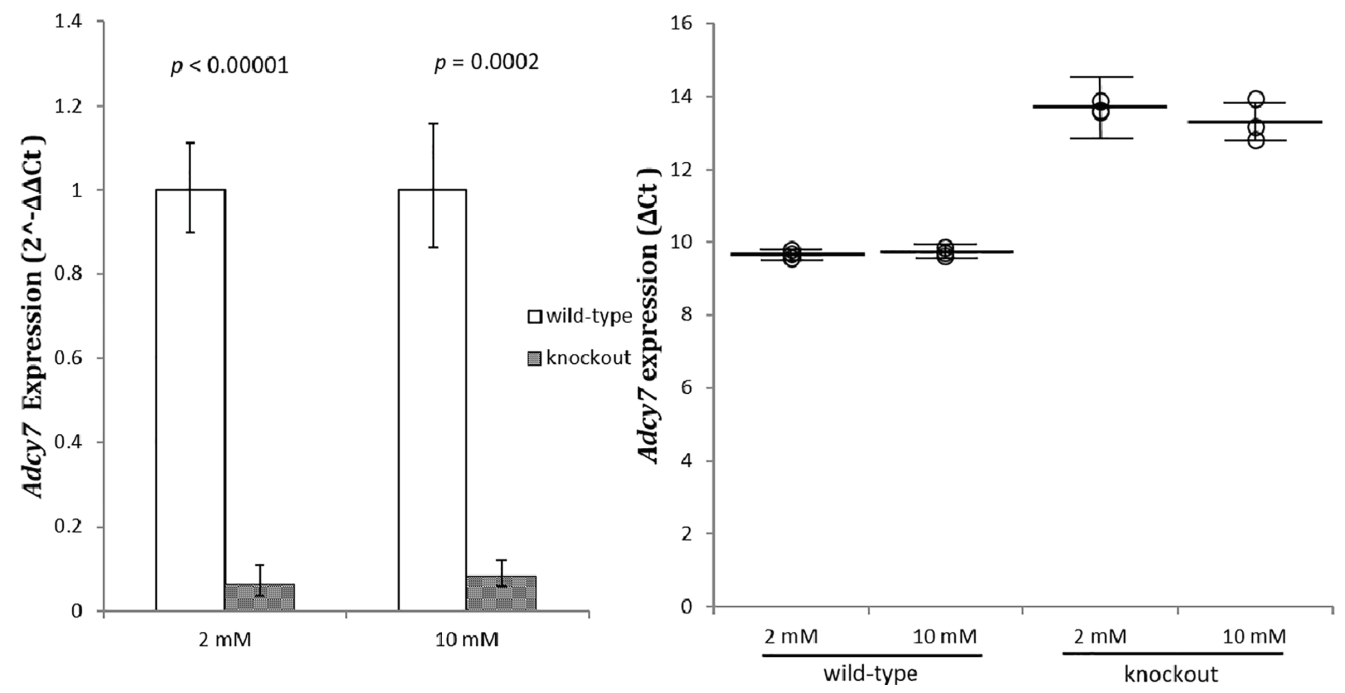

FIGURE 2 | Adcy7 knockout establishment. (A) Sanger sequencing wild-type RIN-m ${ }^{\text {(Adcy7/Adcy7) }}$ (Top) compared to the mutant cell line (bottom) confirmed an insertion creating a frameshift. (B) Amino acid sequencing with a reference (top) shows indel creating a frameshift causing a premature termination codon located in 11 codons downstream. (C) Adcy7 mRNA levels established by quantitative RT-PCR indicating a very low expression level. The CT values were normalized to $\beta$ actin to yield $\Delta \mathrm{CT}$ and $2^{\wedge}-\Delta \Delta \mathrm{CT}$ values presented in dots and bar chart, respectively. Each dot represents an individual sample, whereas the horizontal lines represent the mean and standard error of the mean. $\Delta \mathrm{CT}$ values were then calculated and presented as $2^{\wedge}-\Delta \Delta C T$ values (fold change) in a bar chart. Unpaired $t$-test with delta CT and $\mathrm{SE} \pm$ values were used for statistic test. 
Modified cells showed a significant increase in insulin secretion reaching $54 \%$ at low, and $49 \%$ at high glucose concentration, respectively, compared to the wild-type $(p=0.008, p=0.01)$, (Figure 3C).

\section{Insulin Secretion Pathway}

As Adcy7 converts ATP to cyclic AMP and pyrophosphate, we examined whether the loss of the Adcy7 function influences insulin secretion via the cAMP pathway.

Protein Kinase cAMP-Activated Catalytic Subunits alpha (Prkaca) and beta (Prkacb) and Rap Guanine Nucleotide Exchange Factor 4 (Rapgef4) mRNA, which are highly expressed in pancreatic tissue, were measured as per their role on cAMP activation (27). mRNA levels for the PRKACs subunits indicated no change in the expression level (Figure 4A) while Rapgef4 decreased slightly, but significant (Figure 4B). These results indicated no activation of the cAMP pathway in $\mathrm{RIN}-\mathrm{m}^{(-/-A d c y 7)}$ cells as the cause to increase insulin secretion.

Next, we investigated whether the glucose stimulated-insulin secretion (GSIS) pathway was activated. The glucose uptake and the sensing genes Solute Carrier Family 2 Member 2 (SCL2A2) and Glucokinase $(G C K)$ mRNA levels were measured. Glucose transporter member 2 (Glut2) protein, was extremely upregulated (107.3 fold - $p<0.00001)$ and (107.5 fold $p<0.00001)$ for both low and high glucose concentrations, respectively (Figure 4C). Furthermore, glucokinase protein, which phosphorylates glucose in the first step of GSIS in $\beta$ cells, was also significantly upregulated (3.32 fold - $p<0.00001)$ during low glucose conditions and (3.1 fold - $p=0.0002)$ during high glucose level (Figure 4D).

To investigate the causes of the extreme upregulation of insulin and GSIS genes, Pancreatic and duodenal homeobox 1 (Pdx1), and Forkhead Box Protein A2 (Foxa2) genes expression were measured. $P d x 1$ was significantly up-regulated by 1.7 fold $(p=0.0003)$ in $2 \mathrm{mM}$ glucose and 1.73 fold $(p=0.001)$ in $10 \mathrm{mM}$ compared to the wild-type (Figure $4 \mathrm{E}$ ). On the other hand, Foxa2, which binds to $P d x 1$ to regulate genes responsible for maintaining the mature $\beta$-cell function, were slightly but significantly increased by 1.23 fold $(p=0.006)$ and 1.29 fold $(p=0.05)$ when incubated with $2 \mathrm{mM}$ and $10 \mathrm{mM}$ glucose concentration, respectively, compared to the control (Figure 4F).

\section{DISCUSSION}

In this article, we identified $A D C Y 7$ as a novel candidate genetic cause of $\mathrm{CHI}$. $A D C Y 7$ encodes a membrane-bound adenylate cyclase that converts ATP to cyclic AMP and pyrophosphate. We showed that $A d c y 7$ loss of function leads to excessive insulin secretion and activated the glucose stimulated-insulin secretion pathway.

Mammalian adenylyl cyclases (ACs) consist of nine membrane-bound proteins $\mathrm{AC}$ isoforms, $\mathrm{AC} 1-\mathrm{AC}$, coded by ADCY1-ADCY9 (28). ACs are constructed by two clusters of six transmembrane domains each followed by a cytoplasmic domain $\mathrm{C}_{1}$ and $\mathrm{C}_{2}$ (29). Our patient's $A D C Y 7$ variants were predicted to disrupt the function of the highly conserved domain $\mathrm{C}_{1}$ and $\mathrm{C}_{2}$ justifying further loss-of-function studies. The Asp439 variant is shown to be reside in the gate to the activating domain in $\mathrm{VCl}$ thus likely influencing regulation of substrate uptake (Figure 1A). Gly1045 allow a sharp turn of the loop connecting $\alpha$-helix 15 and $\beta$-strand 19 necessary for IIC2 confirmation (Figure 1B).

Several studies have been linking AC members with insulin secretion and sensitivity. For instance, A gain of function of Adcy 3 in mutagenized mice resistant to diet-induced obesity caused a reduction in both body weight, fat mass, insulin, and glucose levels compared to wild-type when subjected to high fat diet (30). On the contrary, whole-body Adcy5 knockout mice exhibited lower weight, lower fasting glucose, improved glucose tolerance, and increased insulin sensitivity (31). In pancreatic islet study by Hodson and his colleagues, ADCY5 silencing led to impaired glucose-induced cAMP increases and lower ATP concentrations at high glucose levels, in keeping with reduced mRNA expression of ADCY5 in patients with the ADCY5 SNP rs11708067, which increases the risk of type 2 diabetes (32). At least in part, differences in tissue and cell type-specific localization of the individual AC may explain the diversity of regulatory features by different $\mathrm{AC}$ members in CAMP pathway signaling $(24,33)$. Currently, no study reported the association of $A D C Y 7$ with insulin secretion and sensitivity. In the present study, $A D C Y 7$ loss of function was associated with increased insulin secretion, but not with evidence of cAMP alterations at glucose concentrations up to $10 \mathrm{mM}$. This was in line with findings of Hodson et al., where cAMP changes after ADCY5 silencing only occurred at higher glucose levels (32). More studies are needed to understand the differences between the different ACs in glucose metabolism. Compared to the wild-type, our RIN-m ${ }^{(-/-A d c y 7)}$ demonstrated an increase in the acute insulin activity leading to a $54 \%$ higher secretion during hypoglycemia in vitro. These results mimic the pathophysiology of CHI.

Genetic analysis using RT-PCR gene expression indicated that $A d c y 7$ loss of expression upregulates the insulin regulator genes, Ins 1 and Ins2, as well as glucose uptake and sensing by regulating Scl2a2 and Gck via upregulation of $P d x 1$.

$P D X 1$ is a transcriptional factor that regulates the insulin gene. Transfection of a small interfering RNA specific for $P d x 1$ in pancreatic islets insulinoma cell line shows that $P d x 1$ directly regulates the insulin transcription promotor (34). Dox-induced $P d x 1$ expression in embryonic stem cells increased Ins1 and Ins2 mRNA compared to the non-induced cells and corresponding upregulated by $140 \%$ compared to the insulinoma cell line $\beta$ TC6 (35).

Insulin secretion from the pancreatic $\beta$ cell is a tightly regulated process by insulin-tropic factors stimulating intracellular CAMP, or by glucose sensing and uptake. We examined whether intracellular cAMP activation is responsible for increasing insulin secretion in RIN-m $\mathrm{m}^{(-/-A d c y 7)}$ cells, similar to the role of ADCY3 haploinsufficiency in a previous report (36). The mRNA level for PRKACs subunits did not show significant changes, while Rapgef4 decreased only slightly. These results indicated no robust evidence of a cAMP activation pathway in RIN-m ${ }^{(-/-A d c y 7)}$ cells up to $10 \mathrm{mM}$ glucose concentration. Subsequently, the expression analysis of key components of glucose uptake and sensing, Scl2a2, and Gck, revealed an extreme increase in mRNA levels leading to the activation of the glucose stimulated- 
A
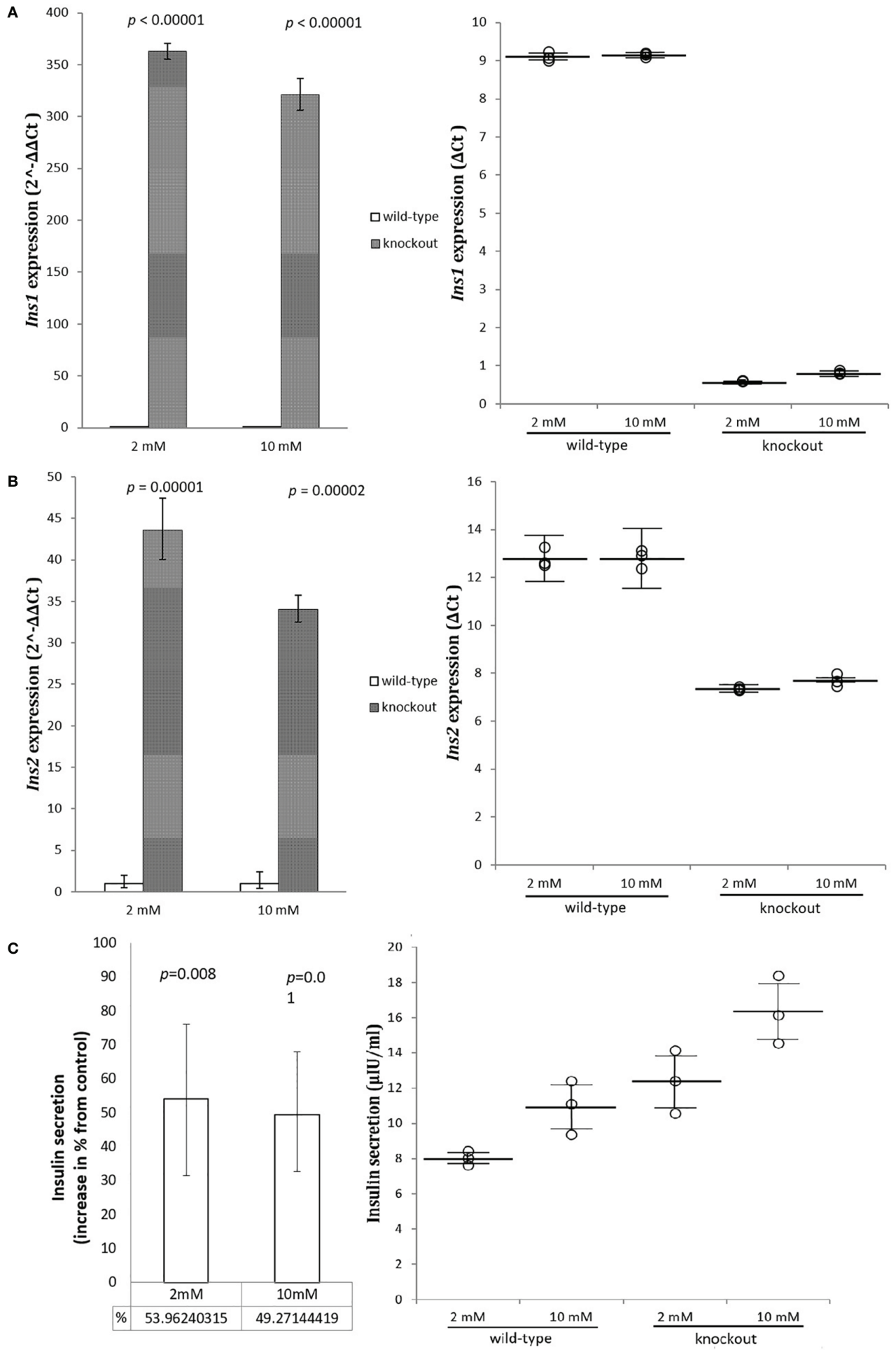

FIGURE 3 | Insulin genes and secretion. RIN-m(- $\left.{ }^{--A d c y} 7\right)$ mRNA level established by quantitative RT-PCR. The CT values were normalized to $\beta$-actin to yield $\Delta C T$ and $2^{\wedge}-\Delta \Delta C T$ values presented in dots and bar chart, respectively. Each dot represents an individual sample, whereas the horizontal lines represent the mean and standard error of the mean. $\Delta C T$ values were then calculated and presented as $2^{\wedge}-\Delta \Delta C T$ values (fold change) in a bar chart. (A) presents the mRNA level of Ins 1 when incubated in low glucose level $2 \mathrm{mM}$ and high glucose level $10 \mathrm{mM}$, while (B) shows the expression level of Ins2 under the same condition. (C) illustrates insulin secretion when incubated for one hour with $2 \mathrm{mM}$ glucose and $10 \mathrm{mM}$ glucose compared to the control. Unpaired t-test with mean of ELISA or delta CT and SE \pm values were used for statistic test. 


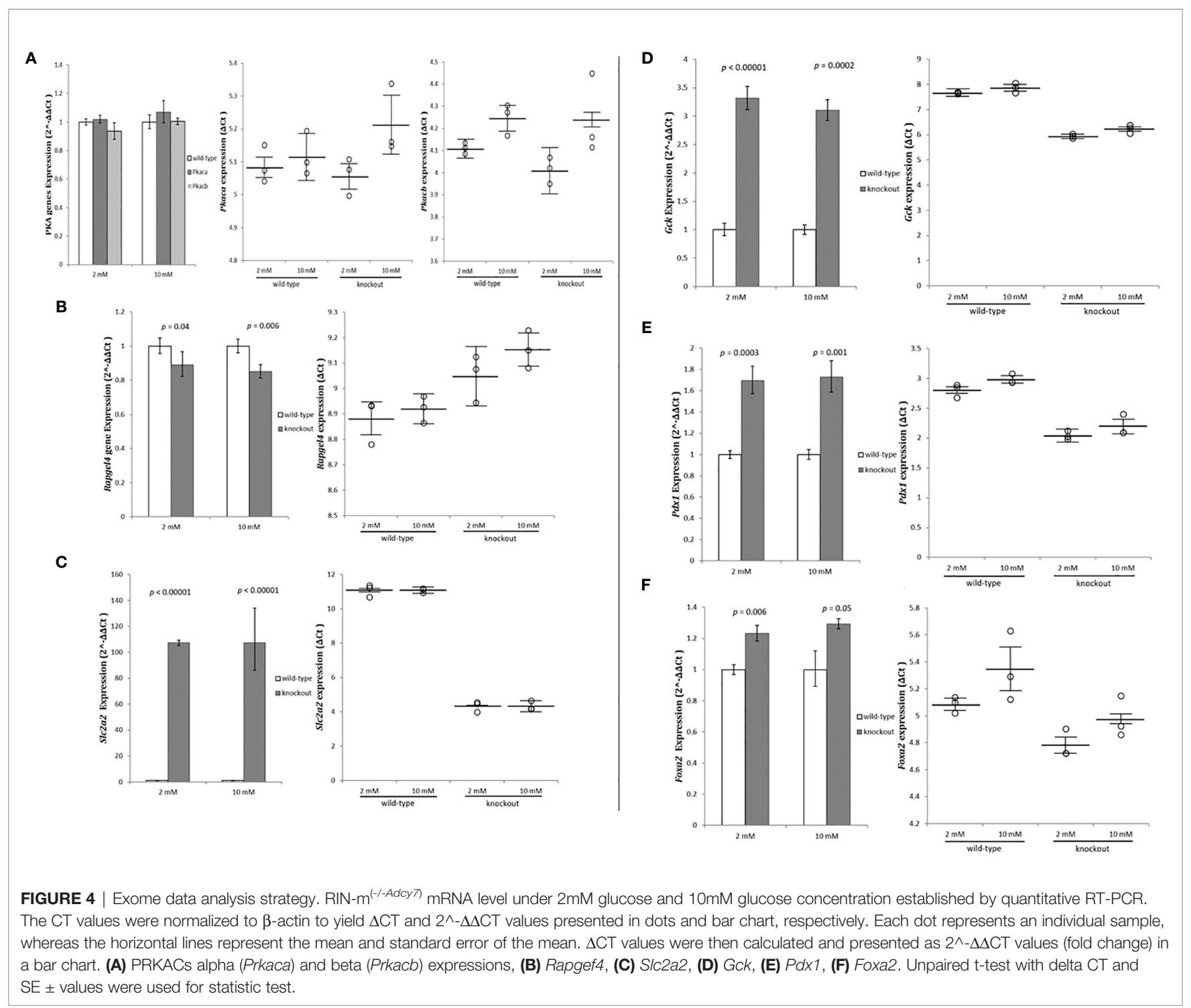

insulin secretion (GSIS) pathway. This due to overexpression of $P D X 1$ gene (37), seen in $\mathrm{RIN}-\mathrm{m}^{(-/-A d c y 7)}$. In $P d x 1$ overexpressed mouse $\beta P d x 1$; Ins $2^{A k i t a}$, insulin secretion, Gck mRNA, and Slc2a2 localization was significantly increaseed compared to the nonmodified Ins $2^{\text {Akita }}$ mouse (38). Foxa2 on the other hand, which binds to $P d x 1$ to regulate genes responsible for maintaining mature $\beta$ cell function (39), was also significantly increased. However, the exact mechanism by which $A D C Y 7$ leads to excessive insulin secretion through GSIS is still not explained by only increasing SLC2A2 and GCK expression during hypoglycemia conditions. In addition, the similarity of insulin secretion percentage between two glucose concentrations compared to wild-type as well as the expression changes seen in this study may also suggest loss of glucose sensitivity rather than an increased glucose phosphorylation. Further analyses with e.g. $\mathrm{KCl}$, sulphonylurea and diazoxide, Gck activity, downstream analyses of both GSIS and cAMP pathways using a full gene expression profile as well as a protein study are needed to fully explain the $A D C Y 7$ mechanism.
RIN-m rat pancreas/islet cell line is a well-characterized cell line that secretes insulin with some concerns raised regarding GSIS and glucose sensitivity. Due to the limitation of a stable and well-characterized human pancreatic cell line, several published studies used RIN-m to investigate target genes concerning insulin secretion and GSIS (40-42). Santina Bruzzone et al. presented the effects of Abscisic acid (ABA) on insulin secretion using RIN-m and human pancreatic islets, concluding that they both show the same effect mediating cAMP on different glucose level (43). In addition, pretreatment and starvation have shown different insulin reactions toward glucose in the RIN-m cell line (42). In this study, RIN-m wild-type and RIN-m ${ }^{(-/-A d c y 7)}$ cultured in $10 \mathrm{mM}$ demonstrated $36.3 \%$, and $32.3 \%$ higher in insulin secretion compared to $2 \mathrm{mM}$, respectively. Nonetheless, the ADCY7 role in glucose induced insulin secretion needs to be further tested in other cell types, e.g. human pancreatic islets, EndoC- $\beta \mathrm{H} 1$ and rat pancreatic cells, BRIN-BD11 and INS-1. 
In conclusion, our study identified a novel candidate gene $A D C Y 7$ to cause CHI. The loss of Adcy7 function in the RIN-m cell line resulted in higher insulin secretion. The complexity of the relationship between $A D C Y 7$ and insulin secretion was at least in part explained by the changes in glucose sensing and glucose uptake in $\beta$-cells, which regulates insulin secretion via the glucose stimulated-insulin secretion pathway. Our finding will potentially open new doors for future work on the adenylyl cyclase complex with an insulin-signaling pathway to obtain better understanding of signaling pathway; secondly to develop a new therapeutic treatment triggering this pathway for patients with diabetes or congenital hyperinsulinism.

\section{DATA AVAILABILITY STATEMENT}

The original contributions presented in the study are included in the Supplementary Material, further inquiries can be directed to the corresponding author.

\section{ETHICS STATEMENT}

The study was approved by The Regional Ethical Committee of Southern Denmark (number. S-VF-20040235). Written informed consent to participate in this study was provided by the participants' legal guardian/next of kin.

\section{REFERENCES}

1. Kapoor RR, Flanagan SE, James C, Shield J, Ellard S, Hussain K. Hyperinsulinaemic Hypoglycaemia. Arch Dis Child (2009) 94:450-7. doi: 10.1136/adc.2008.148171

2. Rahman SA, Nessa A, Hussain K. Molecular Mechanisms of Congenital Hyperinsulinism. J Mol Endocrinol (2015) 54:R119-29. doi: 10.1530/JME-15-0016

3. Helleskov A, Melikyan M, Globa E, Shcherderkina I, Poertner F, Larsen AM, et al. Both Low Blood Glucose and Insufficient Treatment Confer Risk of Neurodevelopmental Impairment in Congenital Hyperinsulinism: A Multinational Cohort Study. Front Endocrinol (Lausanne) (2017) 8:156. doi: 10.3389/fendo.2017.00156

4. Arnoux JB, Verkarre V, Saint-Martin C, Montravers F, Brassier A, Valayannopoulos V, et al. Congenital Hyperinsulinism: Current Trends in Diagnosis and Therapy. Orphanet J Rare Dis (2011) 6:63. doi: 10.1186/17501172-6-63

5. Christiansen CD, Petersen H, Nielsen AL, Detlefsen S, Brusgaard K, Rasmussen L, et al. 18f-Dopa PET/CT and 68Ga-DOTANOC PET/CT Scans as Diagnostic Tools in Focal Congenital Hyperinsulinism: A Blinded Evaluation. Eur J Nucl Med Mol Imaging (2018) 45:250-61. doi: 10.1007/s00259-017-3867-1

6. Pierro A, Nah SA. Surgical Management of Congenital Hyperinsulinism of Infancy. Semin Pediatr Surg (2011) 20:50-3. doi: 10.1053/j.sempedsurg.2010.10.009

7. Beltrand J, Caquard M, Arnoux JB, Laborde K, Velho G, Verkarre V, et al. Glucose Metabolism in 105 Children and Adolescents After Pancreatectomy for Congenital Hyperinsulinism. Diabetes Care (2012) 35:198-203. doi: $10.2337 / \mathrm{dc} 11-1296$

8. van der Steen I, van Albada ME, Mohnike K, Christesen HT, Empting S, Salomon-Estebanez M, et al. A Multicenter Experience With Long-Acting Somatostatin Analogues in Patients With Congenital Hyperinsulinism. Horm Res Paediatr (2018) 89:82-9. doi: 10.1159/000485184

9. Thomas P, Ye Y, Lightner E. Mutation of the Pancreatic Islet Inward Rectifier Kir6.2 Also Leads to Familial Persistent Hyperinsulinemic Hypoglycemia of Infancy. Hum. Mol Genet (1996) 5:1809-12. doi: 10.1093/hmg/5.11.1809

\section{AUTHOR CONTRIBUTIONS}

$\mathrm{KB}, \mathrm{HC}$, and $\mathrm{MB}$ were involved in planning and supervising the project. $\mathrm{HC}$ and EL collected and provided the clinical data. YA and $\mathrm{KB}$ designed the experiments. YA performed the experiments and analyzed the data. YA drafted the manuscript. All authors contributed to the article and approved the submitted version.

\section{FUNDING}

This project was funded by Region of Southern Denmark and The University of Southern Denmark.

\section{ACKNOWLEDGMENTS}

We thank our laboratory staff; Jette Møller for running exome sequencing and Martin J. Larsen for performing the sequencing alignment.

\section{SUPPLEMENTARY MATERIAL}

The Supplementary Material for this article can be found online at: https://www.frontiersin.org/articles/10.3389/fendo.2021.657873/ full\#supplementary-material

10. Thomas PM, Cote GJ, Wohllk N, Haddad B, Mathew PM, Rabl W, et al. Mutations in the Sulfonylurea Receptor Gene in Familial Persistent Hyperinsulinemic Hypoglycemia of Infancy. Science (1995) 268:426-9. doi: 10.1126/science.7716548

11. Christesen HB, Tribble ND, Molven A, Siddiqui J, Sandal T, Brusgaard K, et al. Activating Glucokinase (GCK) Mutations as a Cause of Medically Responsive Congenital Hyperinsulinism: Prevalence in Children and Characterisation of a Novel GCK Mutation. Eur J Endocrinol (2008) 159:27-34. doi: 10.1530/EJE-08-0203

12. Stanley CA, Lieu YK, Hsu BY, Burlina AB, Greenberg CR, Hopwood NJ, et al. Hyperinsulinism and Hyperammonemia in Infants With Regulatory Mutations of the Glutamate Dehydrogenase Gene. N Engl J Med (1998) 338:1352-7. doi: 10.1056/NEJM199805073381904

13. Clayton PT, Eaton S, Aynsley-Green A, Edginton M, Hussain K, Krywawych S, et al. Hyperinsulinism in Short-Chain L-3-hydroxyacyl-CoA Dehydrogenase Deficiency Reveals the Importance of Beta-Oxidation in Insulin Secretion. J Clin Invest (2001) 108:457-65. doi: 10.1172/JCI200111294

14. Otonkoski T, Jiao H, Kaminen-Ahola N, Tapia-Paez I, Ullah MS, et al. Physical Exercise-Induced Hypoglycemia Caused by Failed Silencing of Monocarboxylate Transporter 1 in Pancreatic Beta Cells. Am J Hum Genet (2007) 81:467-74. doi: 10.1086/520960

15. Gonzalez-Barroso MM, Giurgea I, Bouillaud F, Anedda A, Bellanne-Chantelot C, Hubert L, et al. Mutations in UCP2 in Congenital Hyperinsulinism Reveal a Role for Regulation of Insulin Secretion. PLoS One (2008) 3:e3850. doi: 10.1371/journal.pone.0003850

16. Pearson ER, Boj SF, Steele AM, Barrett T, Stals K, Shield JP, et al. Macrosomia and Hyperinsulinaemic Hypoglycaemia in Patients With Heterozygous Mutations in the HNF4A Gene. PLoS Med (2007) 4:e118. doi: 10.1371/ journal.pmed.0040118

17. Stanescu DE, Hughes N, Kaplan B, Stanley CA, De Leon DD. Novel Presentations of Congenital Hyperinsulinism Due to Mutations in the MODY Genes: HNF1A and HNF4A. J Clin Endocrinol Metab (2012) 97: E2026-30. doi: 10.1210/jc.2012-1356 
18. Pinney SE, Ganapathy K, Bradfield J, Stokes D, Sasson A, Mackiewicz K, et al. Dominant Form of Congenital Hyperinsulinism Maps to HK1 Region on 10q. Horm Res Paediatr (2013) 80:18-27. doi: 10.1159/000351943

19. Tegtmeyer LC, Rust S, van Scherpenzeel M, Ng BG, Losfeld ME, Timal S, et al. Multiple Phenotypes in Phosphoglucomutase 1 Deficiency. N Engl J Med (2014) 370:533-42. doi: 10.1056/NEJMc1403446

20. Cabezas OR, Flanagan SE, Stanescu H, Garcia-Martinez E, Caswell R, LangoAllen H, et al. Polycystic Kidney Disease With Hyperinsulinemic Hypoglycemia Caused by a Promoter Mutation in Phosphomannomutase 2. J Am Soc Nephrol (2017) 28:2529-39. doi: 10.1681/ASN.2016121312

21. Hussain K. Diagnosis and Management of Hyperinsulinaemic Hypoglycaemia of Infancy. Horm Res (2008) 69:2-13. doi: 10.1159/000111789

22. Alhaidan Y, Christesen HT, Højlund K, Al Balwi MA, Brusgaard K. A Novel Gene in Early Childhood Diabetes: EDEM2 Silencing Decreases SLC2A2 and PXD1 Expression, Leading to Impaired Insulin Secretion. Mol Genet Genomics (2020) 295:1253-62. doi: 10.1007/s00438-020-01695-5

23. Alhaidan Y, Larsen MJ, Schou AJ, Stenlid MH, Balwi HT, Christesen Y, et al. Exome Sequencing Revealed DNA Variants in NCOR1, IGF2BP1, SGLT2 and NEK11 as Potential Novel Causes of Ketotic Hypoglycemia in Children. Sci Rep (2020) 10(1):2114. doi: 10.1038/s41598-020-58845-3

24. Iyengar R. Molecular and Functional Diversity of Mammalian Gs-stimulated Adenylyl Cyclases. FASEB J (1993) 7:768-75. doi: 10.1096/fasebj.7.9.8330684

25. Yan SZ, Beeler JA, Chen Y, Shelton RK, Tang WJ. The Regulation of Type 7 Adenylyl Cyclase by its C1b Region and Escherichia Coli Peptidylprolyl Isomerase, Slyd. J Biol Chem (2001) 276:8500-6. doi: 10.1074/jbc.M010361200

26. Ludwig MG, Seuwen K. Characterization of the Human Adenylyl Cyclase Gene Family: cDNA, Gene Structure, and Tissue Distribution of the Nine Isoforms. J Recept Signal Transduction Res (2002) 22:79-110. doi: 10.1081/RRS-120014589

27. Fujimoto K, Shibasaki T, Yokoi N, Kashima Y, Matsumoto M, Sasaki T, et al. Piccolo, a Ca2+ Sensor in Pancreatic Beta-Cells. Involvement of CampGEFII.Rim2. Piccolo Complex in cAMP-dependent Exocytosis. J Biol Chem (2002) 277:50497-502. doi: 10.1074/jbc.M210146200

28. Sunahara RK, Dessauer CW, Gilman AG. Complexity and Diversity of Mammalian Adenylyl Cyclases. Annu Rev Pharmacol Toxicol (1996) 36:461-80. doi: 10.1146/annurev.pa.36.040196.002333

29. Tang W-J, Hurley JH. Catalytic Mechanism and Regulation of Mammalian Adenylyl Cyclases. Mol Pharmacol (1998) 54:231-40. doi: 10.1124/mol.54.2.231

30. Pitman JL, Wheeler MC, Lloyd DJ, Walker JR, Glynne RJ, Gekakis N. A Gain-ofFunction Mutation in Adenylate Cyclase 3 Protects Mice From Diet-Induced Obesity. PLoS One (2014) 9:e110226. doi: 10.1371/journal.pone.0110226

31. Ho D, Zhao X, Yan L, Yuan C, Zong H, Vatner DE, et al. Adenylyl Cyclase Type 5 Deficiency Protects Against Diet-Induced Obesity and Insulin Resistance. Diabetes (2015) 64:2636-45. doi: 10.2337/db14-0494

32. Hodson DJ, Mitchell RK, Marselli L, Pullen TJ, Gimeno Brias S, Semplici F, et al. ADCY5 Couples Glucose to Insulin Secretion in Human Islets. Diabetes (2014) 63:3009-21. doi: 10.2337/db13-1607

33. Hanoune J, Defer N. Regulation and Role of Adenylyl Cyclase Isoforms. Annu Rev Pharmacol Toxicol (2001) 41:145-74. doi: 10.1146/annurev.pharmtox.41.1.145
34. Iype T, Francis J, Garmey JC, Schisler JC, Nesher R, Weir GC, et al. Mechanism of Insulin Gene Regulation by the Pancreatic Transcription Factor Pdx-1: Application of pre-mRNA Analysis and Chromatin Immunoprecipitation to Assess Formation of Functional Transcriptional Complexes. J Biol Chem (2005) 280:16798-807. doi: 10.1074/jbc.M414381200

35. Kubo A, Stull R, Takeuchi M, Bonham K, Gouon-Evans V, Sho M, et al. Pdx1 and Ngn3 Overexpression Enhances Pancreatic Differentiation of Mouse Es Cell-Derived Endoderm Population. PLoS One (2011) 6:e24058. doi: 10.1371/journal.pone.0024058

36. Tong T, Shen Y, Lee H-W, Yu R, Park T. Adenylyl Cyclase 3 Haploinsufficiency Confers Susceptibility to Diet-Induced Obesity and Insulin Resistance in Mice. Sci Rep (2016) 6:34179. doi: 10.1038/srep34179

37. Watada H, Kajimoto Y, Umayahara Y, Matsuoka T, Kaneto H, Fujitani Y, et al. The Human Glucokinase Gene Beta-Cell-Type Promoter: An Essential Role of Insulin Promoter Factor 1/PDX-1 in its Activation in HIT-T15 Cells. Diabetes (1996) 45:1478-88. doi: 10.2337/diabetes.45.11.1478

38. Yamamoto Y, Miyatsuka T, Sasaki S, Miyashita K, Kubo F, Shimo N, et al. Preserving Expression of Pdx1 Improves $\beta$-Cell Failure in Diabetic Mice. Biochem Biophys Res Commun (2017) 483:418-24. doi: 10.1016/j.bbrc.2016.12.128

39. Wu KL, Gannon M, Peshavaria M, Offield MF, Henderson E, Ray M, et al. Hepatocyte Nuclear Factor 3beta is Involved in Pancreatic Beta-Cell-Specific Transcription of the Pdx-1 Gene. Mol Cell Biol (1997) 17:6002-13. doi: 10.1128/MCB.17.10.6002

40. Amoreaux WJL, Cuttitta C, Santora A, Blaize JF, Tachjadi J, Idrissi E. Taurine Regulates Insulin Release From Pancreatic Beta Cell Lines. J Biomed Sci (2010) 17(Suppl 1):S11. doi: 10.1186/1423-0127-17-S1-S11

41. Yan H, Li Y, Yang Y, Zhang Z, Zhang G, Sun Y, et al. Protective Effects of Andrographolide Derivative AL-1 on High Glucose-Induced Oxidative Stress in RIN-m Cells. Curr Pharm Des (2016) 22:499-505. doi: 10.2174/ 1381612821666150921110716

42. L’Amoreaux WJ, Cuttitta C, Santora A, Blaize JF, Tachjadi J, El Idrissi A. Taurine Regulates Insulin Release From Pancreatic Beta Cell Lines. J Biomed Sci (2010) 17 Suppl 1:S11. doi: 10.1186/1423-0127-17-S1-S11

43. Bruzzone S, Bodrato N, Usai C, Guida L, Moreschi I, Nano R, et al. Abscisic Acid is an Endogenous Stimulator of Insulin Release From Human Pancreatic Islets With Cyclic ADP Ribose as Second Messenger. J Biol Chem (2008) 283:32188-97. doi: 10.1074/jbc.M802603200

Conflict of Interest: The authors declare that the research was conducted in the absence of any commercial or financial relationships that could be construed as a potential conflict of interest.

Copyright (c) 2021 Alhaidan, Christesen, Lundberg, Balwi and Brusgaard. This is an open-access article distributed under the terms of the Creative Commons Attribution License (CC BY). The use, distribution or reproduction in other forums is permitted, provided the original author(s) and the copyright owner(s) are credited and that the original publication in this journal is cited, in accordance with accepted academic practice. No use, distribution or reproduction is permitted which does not comply with these terms. 